\title{
Perencanaan Lansekap Desa Pertima sebagai Desa Wisata Berkelanjutan di Kecamatan Karangasem Kabupaten Karangasem
}

\author{
IWAN SEMARA PUTRA, NI WAYAN FEBRIANA UTAM ${ }^{1 *}$, \\ ANAK AGUNG GEDE SUGIANTHARA \\ Program Studi Arsitektur Pertamanan, Fakultas Pertanian, Universitas Udayana, \\ Denpasar, 80114, Indonesia \\ *E-mail: wayan_febriana@unud.ac.id
}

\begin{abstract}
Landscape Planning of Pertima Village as Sustainable Tourist Village on District Karangasem.
\end{abstract}

Pertima Village is a village in the province of Bali which has 13 sub village and three indigenous villages which has potency to serve as a tourist village, so it needs to be planned. Tourist villlage is a place which has certain characteristics and values that can be special attraction for tourists with a special interest in rural life. This study aims to determine some potencies and problems which exist in the Pertima Village to develop this village as a tourist village by implementing concept of "Sustainable Tourism Village". The method used in this study were field survey with observation, interview, questionnaire and study literature technique. There were five stages conducted in this research such as site preparation, inventory, analysis, synthesis and planning. The landscape planing were done by using the natural and culture resource approach. Sustainable tourist village apllied was a tourist village that does not pollute or ruin the environment, economically profitable and socially acceptable.

Keywords: landscape planning, Pertima Village, sustainable tourism village, tourism landscape

\section{Pendahuluan}

Bali memiliki keanekaragaman daya tarik wisata yang mengagumkan baik dari alam hingga kebudayaannya. Hal tersebut menjadikan Bali sebagai tempat tujuan utama para wisatawan domestik maupun mancanegara untuk berlibur. Desa Pertima merupakan salah satu desa yang ada di Bali. Desa Pertima memiliki adat istiadat, budaya dan alamnya yang indah yang berupa pantai, sawah dan perkebunan yang dapat menjadi daya tarik wisata sehingga desa ini dapat dikembangkan menjadi desa wisata. Desa wisata adalah suatu wilayah pedesaan yang menawarkan keaslian baik dari segi sosial 
budaya, adat- istiadat, keseharian, arsitektur tradisional, struktur tata ruang desa yang disajikan dalam suatu suatu bentuk integrasi komponen pariwisata antara lain seperti atraksi, akomodasi dan fasilitas pendukung (Zakaria, 2014).

Perencanaan lansekap sangat diperlukan untuk mengembangkan Desa Pertima sebagai desa wisata. Pengembangan infrastruktur yang dilakukan oleh pemerintah saat ini masih kurang untuk mengembangkan potensi yang dimiliki oleh Desa Pertima. Perlu penataan lansekap untuk mengembangkan desa ini karena penataan lansekap merupakan salah satu faktor penting yang dapat menambah daya tarik suatu kawasan.

Rumusan masalah pada penelitian ini yaitu: apa saja potensi serta permasalahan yang menjadi pembatas dalam pengembangan kawasan Desa Pertima menjadi desa wisata, serta bagaimana perencanaan lansekap Desa Pertima yang mendukung sebagai desa wisata. Tujuan dari penelitian ini adalah mengetahui potensi dan permasalahan yang terdapaat di Desa Pertima dalam mengembangkan desa ini sebagai desa wisata dan membuat perencanaan lansekap Desa Pertima sebagai desa wisata.

\section{Metode Penelitian}

\subsection{Tempat dan Waktu Penelitian}

Penelitian ini dilaksanakan di Desa Pertima, Kecamatan Karangasem, Kabupaten Karangasem, Provinsi Bali (Gambar 1). Waktu penelitian dilakukan mulai 15 November 2016 sampaii 28 Februari 2017.

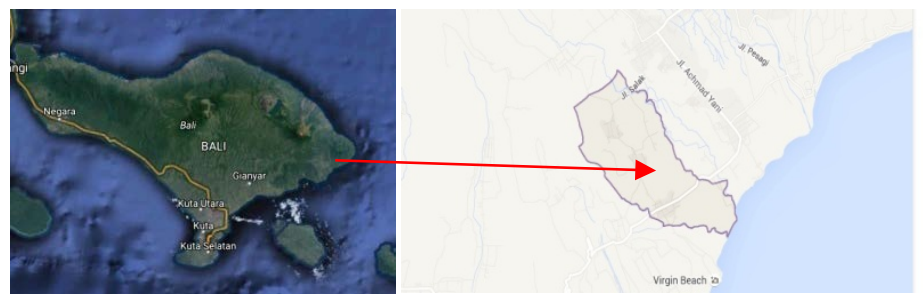

Gambar 1. Peta Lokasi Desa Pertima (Google Earth, 2016)

\subsection{Alat dan Bahan Penelitian}

Alat yang digunakan dalam penelitian ini antara lain: survey kit, perekam suara, kamera, dan komputer. Perangkat lunak yang digunakan antara lain AutoCAD 2016, SketchUP 2016, dan Photoshop X5. Bahan yang digunakan dalam penelitian ini berupa peta Desa Pertima dan data statistik Desa Pertima.

\subsection{Metode Penelitian}

Metode yang digunakan dalam penelitian ini adalah metode survei. Teknik yang digunakan untuk memperoleh data pada penelitian ini melalui observasi, wawancara, kuisoner, dan studi pustaka. Tahapan dalam penelitian ini menggunakan model pendekatan sistematis untuk perencanaan yang dikemukakan oleh Gold (1980) melalui: persiapan tapak, inventarisasi, analisis, sintesis dan perencanaan yang menghasilkan site plan. 


\section{Hasil dan Pembahasan}

\subsection{Kondisi Umum Desa Pertima}

Desa Pertima terletak di Kecamatan Karangasem, Kabupaten Karangasem, Provinsi Bali. Secara geografis Desa Pertima terletak di 8²8'45" LS dan $115^{\circ} 36^{\prime} 2^{\prime \prime}$ BT dengan batas wilayah utara berbatasan dengan Desa Bungaya, timur berbatasan dengan Kelurahan Subagan, Selatan berbatasan dengan Selat Lombok dan barat berbatasan dengan Desa Bugbug serta Desa Tenganan (Profil Desa Pertima,2016). Luas wilayah mencapai 872,59 ha dengan 13 banjar dinas meliputi: Banjar Dinas Perasi Kaler, Banjar Dinas Perasi Kelod, Banjar Dinas Perasi Tengah, Banjar Dinas Perasi Kangin, Banjar Dinas Perasi Kauh, Banjar Dinas Timbrah Desa, Banjar Dinas Timbrah Desa II, Banjar Dinas Timbrah Lambuan, Banjar Dinas Timbrah Manakyeh, Banjar Dinas Beji, Banjar Dinas Asak Kawan, Banjar Dinas Asak Kangin, dan Banjar Dinas Asak Tengah. Tiga Desa Adat yang ada di Desa Pertima yaitu: Desa Adat Perasi, Desa Adat Timbrah dan Desa Adat Asak. Secara umum penggunaan lahan di Desa Pertima terbagi menjadi lahan terbangun dan lahan terbuka. Luas area lahan terbangun seluas 92,61 ha dan area terbuka seluas 779,98 ha (Profil Desa Pertima, 2016).

Desa Pertima memiliki iklim tropis dengan suhu berkisar $26^{\circ} \mathrm{C}$ saat malam hari hingga $31^{\circ} \mathrm{C}$ saat siang hari, dengan kelembaban udara rata-rata $83 \%$ pertahun. Berdasarkan klasifikasi iklim Schmidt-Ferguson, Desa Pertima memiliki tipe iklim B, sedangkan berdasarkan klasifikasi iklim Oldeman, Desa Pertima memiliki tipe iklim D3 (Badan Informasi Geospasial, 2011). Pada tahun 2015 curah hujan tertinggi terdapat pada bulan Januari sebesar $494 \mathrm{~mm}$ dengan jumlah hari hujan sebanyak 19 hari sedangkan curah hujan tersedikit terjadi pada bulan September sebesar $0 \mathrm{~mm}$ dengan tanpa hari hujan (BPS Kabupaten Karangasem, 2016). Jenis tanah yang dominan pada kawasan Desa Pertima yaitu tanah regosol, sedangkan area sekitaran pantai di Desa Pertima, jenis tanahnya yaitu tanah aluvial dan tanah pasir (BPN Kabupaten Karangasem, 2015).

Jalan umum yang ada di Desa Pertima meliputi jalan provinsi sepanjang $2 \mathrm{~km}$, jalan kabupaten sepanjang $5 \mathrm{~km}$ dan jalan desa sepanjang $12 \mathrm{~km}$ (Dinas PUPR Kabupaten Karangasem, 2016). Kondisi jalan provinsi dan jalan kabupaten di desa ini cukup bagus dengan jalan beraspal sedangkan kondisi jalan desa yang ada di Desa Pertima cukup bagus sepanjang 8,63 km dan rusak sepanjang 3,37 km (Bappeda Kabupaten Karangasem, 2015).

Vegetasi yang ada di Desa Pertima berupa tanaman pangan dan tanaman hortikultura. Komoditi utama desa ini antara lain padi (Oryza sativa L) kelapa (Cocos nucifera) dan ketela pohon (Manihot esculenta). Jenis tanaman pangan yang ada di Desa ini berupa serealia, biji-bijan dan umbi-umbian. Sedangkan jenis tanaman hortikultura yang ada di Desa ini berupa tanaman buah, tanaman sayuran, tanaman hias, dan tanaman obat-obatan.

Struktur perekonomian Desa Pertima masih bercorak agraris yang menitikberatkan pada sektor pertanian dimana 80\% penduduk desa ini berprofesi sebagai petani. Sektor lain yang menjadi economic base dan menonjol selain pertanian antara lain industri rumah tangga, perdagangan dan pariwisata. Struktur penduduk menurut pendidikan menunjukan 
kualitas SDM yang dimiliki Desa Pertima yaitu yang berusia pada pendidikan dasar usia 716 tahun yang belum pernah sekolah sebanyak 0,3\%, mengikuti pendidikan $97,8 \%$ dan $1,8 \%$ putus sekolah. Sedangkan penduduk yang berusia 16 tahun keatas yang belum pernah bersekolah sebanyak $0,23 \%$, sedang mengikuti pendidikan $97.89 \%$ dan 1,88\% tidak bersekolah lagi, baik pada tingkat lanjutan atau perguruan tinggi. Kebudayaan Desa Pertima tidak terlepas dan diwarnai oleh Agama Hindu dengan filosofi "Tri Hita Karana" (Profil Desa Pertima, 2016).

\subsection{Potensi dan Permasalahan}

Desa Pertima memiliki berbagai potensi dan permasalahan untuk dijadikan sebagai desa wisata. Potensi dan permasalahan tersebut merupakan kriteria-kriteria sebuah desa wisata yang meliputi atraksi, jarak tempuh, besaran desa (menyangkut masalah-masalah jumlah rumah, jumlah penduduk, karakteristik dan luas wilayah desa), sistem kepercayaan dan kemasyarakatan serta ketersediaan infrastruktur (UNDP dan WTO, 1981). Tabel 1 menjelaskan analisis, sintesis potensi dan permasalahan yang ada di Desa Pertima.

Tabel 1. Analisis, Sintesis Potensi dan Permasalahan di Desa Pertima

\begin{tabular}{|c|c|c|c|c|}
\hline \multirow{2}{*}{ No } & \multirow{2}{*}{ Data } & \multicolumn{2}{|c|}{ Analisis } & \multirow{2}{*}{ Sintesis } \\
\hline & & Potensi & Permasalahan & \\
\hline 1 & $\begin{array}{l}\text { Letak dan luas wilayah } \\
(b, c)\end{array}$ & $\begin{array}{ll}\text { - Jarak yang dekat } \\
\text { dengan Kota } \\
\text { Amlapura dan } \\
\text { obyek wisata } \\
\text { lainnya } \\
\text { - Luas wilayah Desa } \\
\text { Pertima }\end{array}$ & $\begin{array}{l}\text { - Lokasi tapak belum } \\
\text { terawat dan tertata } \\
\text { dengan baik } \\
\text { - Letak desa jauh } \\
\text { dengan pusat Kota } \\
\text { Denpasar }\end{array}$ & $\begin{array}{l}\text { Dengan menonjolkan } \\
\text { lokasi good view, potensi } \\
\text { desa dan menempatkan } \\
\text { fasilitas-fasilitas penunjang } \\
\text { agar pengunjung dapat } \\
\text { menikmati keindahan desa }\end{array}$ \\
\hline 2 & $\begin{array}{l}\text { Penggunaan lahan } \\
(a, c)\end{array}$ & $\begin{array}{l}\text { - Lahan terbangun } \\
\text { - Lahan tidak } \\
\text { terbangun }\end{array}$ & $\begin{array}{l}\text { Lahan belum tertata } \\
\text { dengan baik }\end{array}$ & $\begin{array}{l}\text { Melakukan perencanaan } \\
\text { kawasan dengan membuat } \\
\text { zonasi sehingga lahan } \\
\text { dapat dimanfaatkan denga } \\
\text { baik }\end{array}$ \\
\hline 3 & $\begin{array}{l}\text { Iklim } \\
\text { (c) }\end{array}$ & $\begin{array}{ll}\text { - } & \text { Iklim tropis Desa } \\
\text { Pertima } \\
\text { - } \quad \text { Klasifikasi iklim } \\
\text { Schmidt-Ferguson } \\
\text { type iklim B }\end{array}$ & $\begin{array}{l}\text { Suhu saat siang hari } \\
\text { tidak ideal }\end{array}$ & $\begin{array}{l}\text { Meletakkan tanaman } \\
\text { peneduh yang ditata } \\
\text { dengan baik sehingga } \\
\text { memberikan nilai estetika } \\
\text { dan menghasilkan iklim } \\
\text { yang sesuai standar } \\
\text { keyamanan }\end{array}$ \\
\hline 4 & $\begin{array}{l}\text { Tanah dan topografi } \\
\text { (c) }\end{array}$ & $\begin{array}{l}\text { - Jenis tanah } \\
\text { regosol }\end{array}$ & $\begin{array}{l}\text { - Kondisi tanah labil } \\
\text { sehingga mudah } \\
\text { longsor pada akses } \\
\text { jalan menuju pantai }\end{array}$ & $\begin{array}{l}\text { Membuat retaining wall } \\
\text { pada akses jalan menuju } \\
\text { pantai dan menambah } \\
\text { vegetasi }\end{array}$ \\
\hline 5 & $\begin{array}{l}\text { Sumber daya air } \\
\text { (c) }\end{array}$ & $\begin{array}{l}\text { - } \quad \text { Sumber mata air } \\
\text { - } \quad \text { Air PDAM } \\
\text { - } \quad \text { Air Sumur }\end{array}$ & $\begin{array}{l}\text { Air PDAM kadang- } \\
\text { kadang mati }\end{array}$ & $\begin{array}{l}\text { Memanfaatkan sumber } \\
\text { mata air seoptimal } \\
\text { mungkin }\end{array}$ \\
\hline 6 & $\begin{array}{l}\text { Aksesibilitas } \\
\text { (b) }\end{array}$ & $\begin{array}{l}\text { - Jalan provinsi } \\
\text { - Jalan kabupaten } \\
\text { - Jalan desa }\end{array}$ & $\begin{array}{l}\text { - Kondisi jalan desa } \\
\text { rusak sepanjang } \\
3.373 \mathrm{~m}\end{array}$ & $\begin{array}{l}\text { - Memperbaiki jalan } \\
\text { desa yang rusak dan } \\
\text { menggunakan }\end{array}$ \\
\hline
\end{tabular}




\begin{tabular}{|c|c|c|c|c|}
\hline \multirow{2}{*}{ No } & \multirow{2}{*}{ Data } & \multicolumn{2}{|c|}{ Analisis } & \multirow{2}{*}{ Sintesis } \\
\hline & & Potensi & Permasalahan & \\
\hline & & & $\begin{array}{l}\text { - } \\
\text { Tidak ada jalur } \\
\text { evakuasi bencana } \\
\text { kebakaran, banjir } \\
\text { dan gunung } \\
\text { meletus }\end{array}$ & $\begin{array}{l}\text { kombinasi paving } \\
\text { block dan aspal } \\
\text { sebagai alas jalan } \\
\text { desa } \\
\text { - } \\
\text { Membuat jalur } \\
\text { evakuasi bencana } \\
\text { kebakaran }\end{array}$ \\
\hline 7 & $\begin{array}{l}\text { Vegetasi } \\
\text { (c) }\end{array}$ & $\begin{array}{l}\text { - } \quad \text { Tanaman pangan } \\
\text { - Tanaman } \\
\text { hortikultura }\end{array}$ & $\begin{array}{l}\text { - Tanaman pada tepi } \\
\text { jalan raya kurang } \\
\text { terawat dan tertata } \\
\text { - Kurangnya } \\
\text { tanaman fungsi } \\
\text { ekologis serta } \\
\text { tanaman fungsi } \\
\text { arsitektural pada } \\
\text { tepi jalan raya }\end{array}$ & $\begin{array}{l}\text { - Merawat dan menata } \\
\text { vegetasi pada tepi } \\
\text { jalan raya melibatkan } \\
\text { seluruh elemen } \\
\text { masyarakat } \\
\text { - } \\
\text { Menambahkan } \\
\text { tanaman fungsi } \\
\text { ekologis serta } \\
\text { tanaman fungsi stetika } \\
\text { dan arsitektural pada } \\
\text { tepi jalan raya }\end{array}$ \\
\hline 8 & $\begin{array}{l}\text { Fasilitas dan utilitas } \\
\text { (e) }\end{array}$ & $\begin{array}{l}\text { - } \text { Fasilitas kesehatan } \\
\text { - } \text { Pura } \\
\text { - } \text { Kantor desa } \\
\text { - Poko atau kios } \\
\text { - Perumahan } \\
\text { - Pedestrian } \\
\text { - Villa } \\
\text { - Restoran } \\
\text { - Rambu-rambu lalu } \\
\text { - } \text { lintas } \\
\text { - } \text { Aempat parkir } \\
\text { - Listrik }\end{array}$ & $\begin{array}{ll}\text { - } & \text { Kantor Desa } \\
\text { Pertima kurang } \\
\text { terawat } \\
\text { - } \text { Kurang tersedianya } \\
\text { tempat } \\
\text { pembuangan } \\
\text { sampah } \\
\text { - } \quad \text { Terdapat } \\
\text { kerusakan pada } \\
\text { konstruksi } \\
\text { pedestrian } \\
\text { Tempat parkir } \\
\text { belum tertata } \\
\text { dengan baik }\end{array}$ & $\begin{array}{ll}\text { - } & \text { Menambah sarana } \\
\text { dan prasarana } \\
\text { infrastuktur penunjang } \\
\text { Desa Wisata } \\
\text { - } \quad \text { Memperbaiki } \\
\text { infrasitruktur yang ada } \\
\text { - } \quad \text { Melakukan } \\
\text { perencanaan } \\
\text { lansekap }\end{array}$ \\
\hline 9 & $\begin{array}{l}\text { Visual } \\
\text { (a) }\end{array}$ & $\begin{array}{l}\text { - } \quad \text { Virgin Beach } \\
\text { - } \text { Persawahan } \\
\text { - } \quad \text { Perkebunan } \\
\text { - } \text { Bukit Apen }\end{array}$ & $\begin{array}{ll}\text { - } & \text { TPS tidak terawat } \\
\text { - } & \text { Sengan baik } \\
\text { Sampah } \\
\text { menumpuk pada } \\
\text { saluran drainase } \\
\text { - } \quad \text { Terdapat sampah } \\
\text { di tempat umum }\end{array}$ & $\begin{array}{l}\text { Menata TPS, memilih } \\
\text { lokasi yang tepat untuk } \\
\text { TPS dan menyediakan } \\
\text { fasilitas tempat } \\
\text { pembuangan sampah di } \\
\text { tempat umum }\end{array}$ \\
\hline 10 & $\begin{array}{l}\text { Aspek ekonomi, sosial } \\
\text { dan budaya } \\
(a, c, d)\end{array}$ & $\begin{array}{ll}\text { - } & \text { Struktur } \\
& \text { perekonomian } \\
& \text { bercorak agraris } \\
\text { - } & \text { Perdagangan } \\
\text { - } & \text { Industri rumah } \\
& \text { tangga } \\
\text { - } & \text { Pariwisata } \\
\text { - } & \text { Memiliki berbagai } \\
& \text { tradisi dan budaya } \\
\end{array}$ & $\begin{array}{l}\text { Terdapat warga yang } \\
\text { kurang peduli dengan } \\
\text { potensi yang dimilki } \\
\text { Desa Pertima }\end{array}$ & $\begin{array}{l}\text { Melakukan perencanaan } \\
\text { lansekap untuk menjadikan } \\
\text { Desa Pertima sebagai } \\
\text { desa wisata sehingga } \\
\text { penduduk setempat } \\
\text { memperoleh pemasukan } \\
\text { lebih dan dapat mengelola } \\
\text { potensi yang dimiliki desa. }\end{array}$ \\
\hline
\end{tabular}

Sumber: Observasi Lapangan, 2016

Keterangan: Kriteria Desa Wisata
a. Atraksi
d. Sistem Kepercayaan dan Kemasyarakatan
b. Jarak Tempuh
e. Infrastruktur
c. Besaran Desa 


\subsection{Konsep Dasar}

Konsep dasar yang digunakan dalam perencanaan ini adalah konsep "Desa Wisata Berkelanjutan". Konsep dasar perencanaan ini dilakukan dengan pendekatan sumber daya, dengan menentukan tipe-tipe alternatif aktivitas rekreasi dan wisata berdasarkan pertimbangan kondisi serta situasi sumber daya, sehingga menciptakan kawasan desa wisata berkelanjutan, yang bisa menjamin keberlangsungan atau keberadaan sumber daya alam dan kehidupan sosial-budaya serta memberikan manfaat ekonomi bagi masyarakat setempat hingga generasi yang akan datang. Arti berkelanjutan adalah kawasan desa wisata yang tidak mencemari atau merusak lingkungan, menguntungkan secara ekonomi, dan dapat diterima oleh masyarakat (Subadra, 2016). Perencanaan Lansekap Desa Pertima sebagai Desa Wisata Berkelanjutan dikembangkan menjadi rencana tata ruang, rencana tata hijau dan rencana sirkulasi.

\subsection{Konsep Pengembangan}

\subsubsection{Rencana Tata Ruang}

Konsep tata ruang yang direncanakan disesuaikan dengan potensi tapak dengan memperhatikan aspek lingkungan, aspek sosial budaya dan aspek ekonomi. Pembagian ruang pada tapak di bagi dalam tiga zona yaitu zona lingkungan, zona sosial budaya, dan zona ekonomi seperti yang dapat dilihat pada Gambar 2. Batasan setiap zona dalam perencanaan desa wisata berkelanjutan di Desa Pertima yaitu: zona lingkungan seluas 272,42 ha $(31,23 \%)$, zona sosial budaya seluas 117,77 ha $(12,92 \%)$ dan zona ekonomi seluas 487,35 ha $(55,85 \%)$.

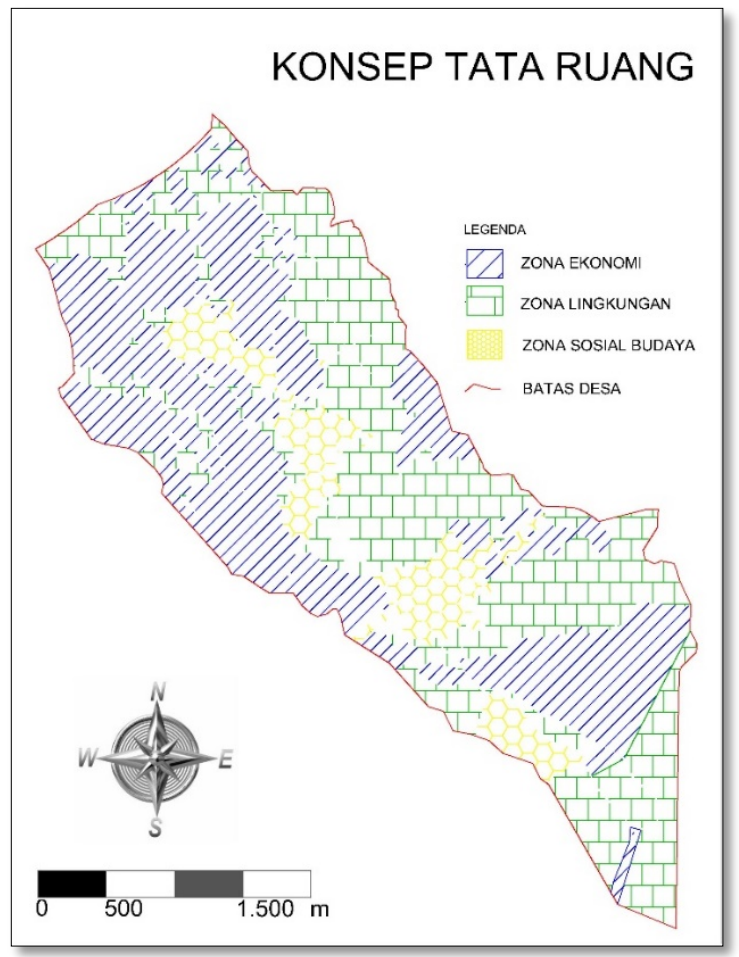

Gambar 2. Konsep Tata Ruang (Hasil Pengolahan, 2017) 


\subsubsection{Rencana Tata Hijau}

Tata hijau yang direncanakan disesuaikan dengan tujuan perencanaan dan kebutuhan masyarakat, sementara pemilihan dan peletakannya disesuaikan dengan tujuan dan fungsi tanaman. Fungsi tata hijau yang direncanakan pada tapak perencanaan yaitu: fungsi ekologis, fungsi arsitektural, fungsi sosial budaya dan fungsi ekonomi yang dapat dilihat pada Gambar 3A (Lokakarya Ruang Terbuka Hijau, 2005).

\subsubsection{Rencana Tata Sirkulasi}

Berdasarkan konsep ruang yang direncanakan, terdapat tiga jenis sirkulasi yaitu: sirkulasi primer, sirkulasi sekunder dan sirkulasi tersier (Gambar 3B). Hubungan jalur sirkulasi dengan ruang dibedakan menjadi dua yaitu: jalur sirkulasi kendaraan dan jalur sirkulasi manusia. Sirkulasi primer adalah jalan akses utama wisatawan mulai dari area penerimaan (welcome area) hingga area pelayanan dengan pola sirkulasi linear. Sirkulasi sekunder adalah jalan akses yang menghubungkan zona sosial budaya dengan zona ekonomi dan zona lingkungan dengan pola sirkulasi radial. Sementara itu sirkulasi tersier adalah akses jalan setapak yang menghubungkan antar fasilitas-fasilitas dan objek-objek dalam zona dengan pola sirkulasi jaringan.

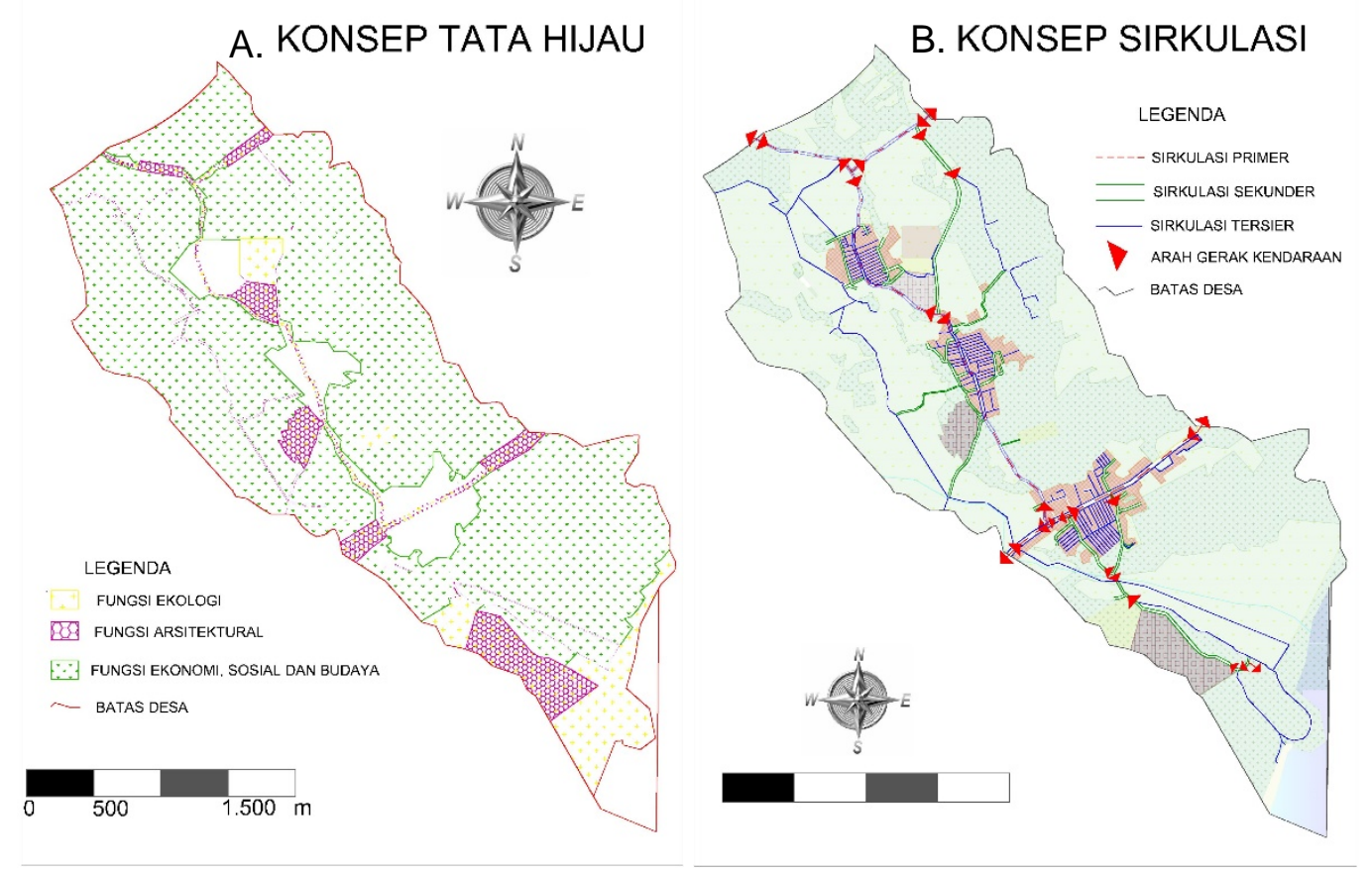

Gambar 3. Konsep Tata Hijau (A) dan Sirkulasi (B) (Sumber: Hasil Pengolahan, 2017)

\subsection{Perencanaan Lansekap}

Konsep tata ruang, tata hijau dan tata sirkulasi yang telah dijabarkan, selanjutnya akan digambarkan dalam bentuk site plan (Gambar 4). 


\subsubsection{Perencanaan Zona Lingkungan}

Perencanaan zona lingkungan meliputi area perkebunan, bukit dan tempat pengelolaan limbah di Desa Pertima. Area perkebunan (Taman gumi banten dan taman obat) dan Bukit Apen (Bumi perkemahan) dijadikan sebagai kawasan yang memiliki fungsi pokok perlindungan terhadap ekosistem dan biodiversitas, konservasi sumber daya air, dan minimalisir gangguan atmosfer, area pengelolaan limbah berfungsi untuk penampungan limbah padat maupun cair yang organik, anorganik dan B3 (Bahan beracun dan berbahaya). Tata hijau yang diterapkan yaitu: fungsi ekologis, fungsi sosial budaya dan fungsi ekonomi. Tanaman yang digunakan yaitu tanaman hortikultura sayur, buah dan obat-obatan. Sirkulasi pada zona ini yaitu sirkulasi tersier berupa jalan tanah dengan lebar 2-3 m merupakan jalur sirkulasi manusia pada area perkebunan dan Bukit Apen. Sedangkan pada area pengelolaan limbah beralas paving dengan lebar jalan 2 meter untuk jalur sirkulasi manusia dan $6 \mathrm{~m}$ untuk jalur sirkulasi kendaraan bermotor, kendaraan ringan dan kendaraan berat. Aktifitas yang dapat dilakukan pada zona ini antara lain: berkemah, mempelajari ekosistem, dan belajar mengolah sampah. Fasilitas yang terdapat pada zona ini antara lain: pura, toko perlengkapan alat kemah, papan informasi, gazebo, kolam penampungan limbah, gedung pengolahan kompos, kolam limbah cair, bank sampah dan toilet umum

\subsubsection{Perencanaan Zona Sosial Budaya}

Pada perencanaan ini, zona sosial budaya meliputi kawasan pura, pemukiman dan area pemakaman penduduk di Desa Adat Asak, Desa Adat Timbrah dan Desa Adat Perasi yang merupakan tempat berlangsungnya kehidupan sosial budaya masyarakat desa Pertima. Tata hijau yang diterapkan pada zona ini adalah fungsi ekologis, fungsi arsitektural, fungsi sosial budaya dan fungsi ekonomi, tanaman yang diterapkan antara lain: ketapang kencana (Terminalia mantaly), bugenvil (Bougainvilea spectabilis), kaca piring (Gardenia jasminoides),Soka (Ixora sp), beringin (Ficus benjamina),kamboja Plumeria sp, dan tanaman lain yang tumbh dengan baik pada ketinggian 0-250 m dpl. Sirkulasi pada zona ini yaitu sirkulasi primer berupa jalan provinsi, jalan kabupaten dan jalan desa yang terdiri dari jalur sirkulasi manusia dan jalur sirkulasi kendaraan.

Pada zona budaya pengunjung dapat melakukan berbagai aktifitas antara lain: menyaksikan berbagai pelaksanaan tradisi dan budaya yang ada di desa Pertima seperti Usaba Kaulu, Usaba Kedasa, Tari Rejang, Usaba Sumbhu dan berbagai upacara agama atau tradisi lainnya yang ada di Desa Pertima serta wisatawan dapat mengabadikan momen pelaksanaan tradisi tersebut, selain itu pengunjung dapat mempelajari cara pembuatan sarana upakara, belajar tari Bali, belajar membuat jajanan Bali, dan belajar memainkan gamelan. Fasilitas pendukung yang ada pada zona budaya antara lain: wantilan, pura, akses jalan, rumah warga, pusat informasi, papan informasi, pedestrian, tempat parkir, tempat sampah, toilet umum, dan lampu penerangan jalan. 


\subsubsection{Perencanaan Zona Ekonomi}

Zona ekonomi merupakan zona yang dapat memberikan dampak ekonomi bagi masyarakat Desa Pertima yang meliputi area persawahan, peternakan dan pantai (Virgin Beach). Tata hijau pada zona ini yaitu: fungsi arsitektural, fungsi sosial budaya dan fungsi ekonomi, tanaman yang digunakan antara lain: padi (Oryza sativa L), pacar air (Impatiens balsamina), kenikir (Cosmos caudatus K), beringin (Ficus benjamina), ketapang kencana (Terminalia mantaly), kamboja (Plumeria sp) dan tanaman lain yang tumbh dengan baik pada ketinggian 0-250 $\mathrm{m}$ dpl. Sirkulasi pada zona ini yaitu sirkulasi tersier berupa jalur sirkulasi manusia dan jalur sirkulasi kendaraan yang menhubungkan fasilitas-fasilitas penunjang pada zona ini.

Pada area persawahan dan peternakan pengunjung dapat melakukan berbagai aktifitas wisata agro antara lain: bertani secara tradisioal, trackingi, menikmati pemandangan pre-wedding, belajar berternak, dan mempelajari perilaku hewan. Pada area pantai pengunjung dapat melakukan berbagai aktifitas antara lain: berjemur, berenang snorkeling, sailing, pre-wedding, dan voli pantai. Fasilitas yang terdapat pada zona ini antara lain: pura, akses jalan, gazebo, kandang ternak, kantor pengelola, restoran, tempat parkir, toilet umum untuk mendukung berbagai aktifitas rekreasi wisatawan. 


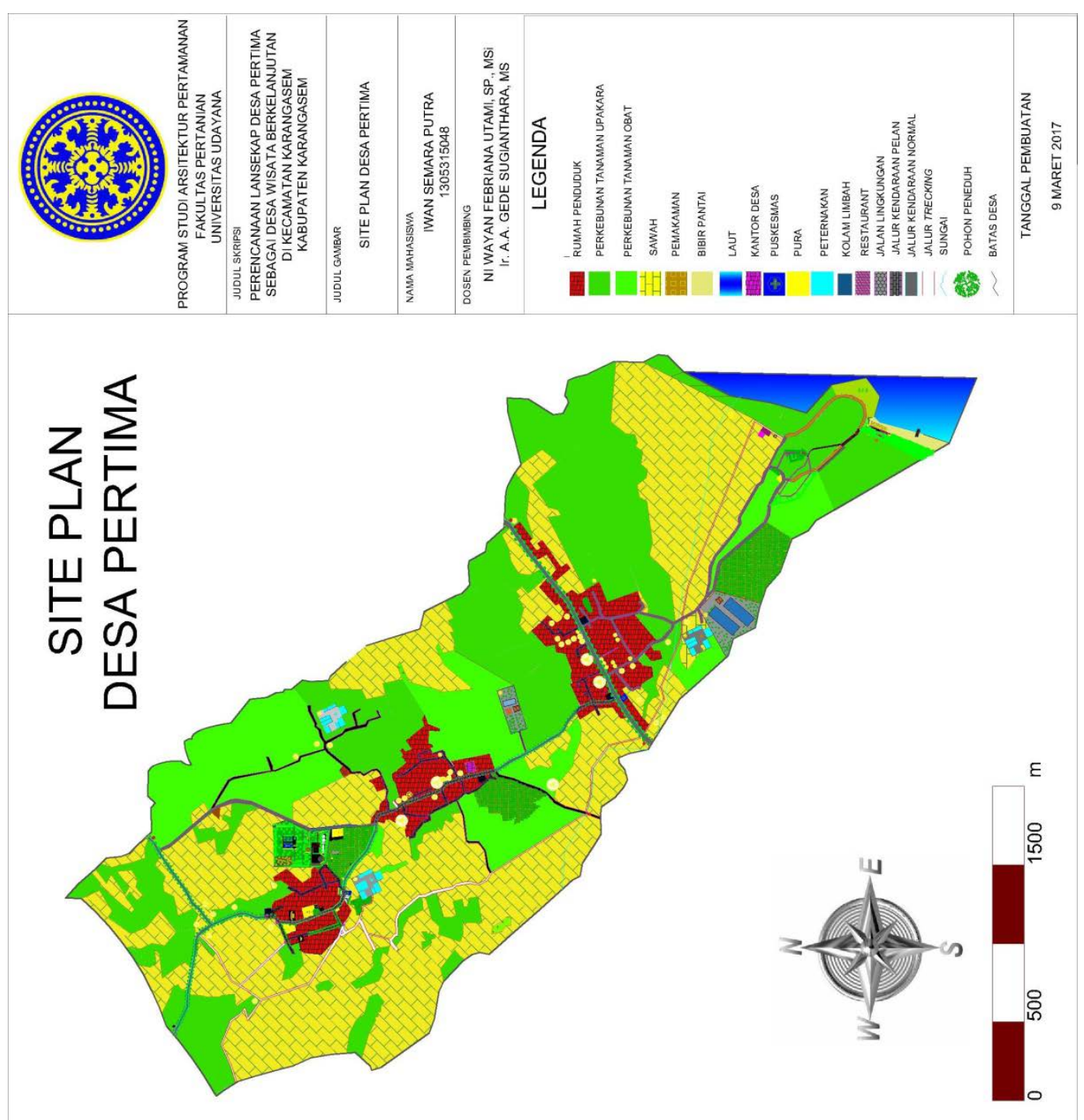

Gambar 4. Site Plan Desa Pertima (Hasil Pengolahan, 2017)

\section{Simpulan dan Saran}

\subsection{Simpulan}

Potensi yang dimiliki Desa Pertima dalam mewujudkan desa wisata dilihat dari kriteria desa wisata antara lain: a) atraksi berupa: pantai, sawah, perkebunan, Bukit Apen, Usaba Kasa, Tari Rejang Desa Adat Asak, Usaba Kaulu, Meami-amianan dan Usaba Sumbu, b) Jarak tempuh yaitu: dekat dengan Kota Amlapura, Obyek Wisata Candidasa, Taman Soekasada Ujung dan Taman Tirta Gangga, c) Besaran desa antara lain: jumlah rumah penduduk, jumlah penduduk dan karakteristik desa, d) Sistem kepercayaan dan kemasyarakatan yaitu: menganut Agama Hindu dengan filosofi Tri Hita Karana, dan e) Ketersedia infrastruktur antara lain: fasilitas dan pelayanan transportasi, fasilitas kesehatan, pura, air dan listrik yang cukup memadai untuk menunjang kebutuhan masyarakat dan pengunjung. 
Permasalahan yang dihadapi Desa Pertima dalam mewujudkan desa ini sebagai desa wisata dilihat dari kriteria desa wisata yaitu: a) jarak tempuh jauh dari Kota Denpasar, b) Besaran desa antara lain: lahan belum tertata dengan baik, kondisi iklim siang hari kurang ideal dan kurangnya tanaman peneduh di tepi jalan kabupaten, c) Ketersediaan infrastruktur antara lain: masalah persampahan, sistem pengolahan air limbah yang tidak optimal, jalan desa rusak sepanjang $3.373 \mathrm{~m}$, kondisi eksisting konstruksi drainase buruk, tempat parkir kurang tertata dengan baik, saluran irigasi tidak mengairi sawah secara maksimal dan terdapat beberapa fasilitas pelayanan publik dengan kondisi kurang terawat.

Konsep dasar perencanaan lansekap Desa Pertima sebagai desa wisata adalah "Desa Wisata Berkelanjutan". Konsep pengembangan dari konsep dasar tersebut terdiri dari rencana tata ruang, rencana tata hijau, dan rencana tata sirkulasi. Rencana tata ruang terdiri dari zona lingkungan, zona sosial budaya, dan zona ekonomi. Rencana tata hijau terdiri dari fungsi ekologi, fungsi arsitektural serta fungsi sosial budaya dan fungsi ekonomi. Rencana sirkulasi primer, sirkulasi sekunder dan sirkulasi tersier.

\subsection{Saran}

Hasil dari perencanaaan lansekap ini dapat dijadikan masukan dan pertimbangan dalam pengguanaan lahan bagi pemerintah Desa Pertima atau Kabupaten Karangasem, masyarakat setempat dan pihak-pihak terkait untuk dikembangkan sebagai desa wisata yang berkelanjutan.

\section{DAFTAR PUSTAKA}

Badan Informasi Geosfasial. 2011. Peta Klasifikasi Iklim Provinsi Bali Priode 1991-2010. Badan Meteorologi, Klimatologi, dan Geofisika Provinsi Bali.

Bappeda. 2015. Rencana Penataan Jalan Lingkungan di Kecamatan Karangasem. Badan Perencanaan Pembangunan Daerah Kabupaten Karangasem.

BPS Kabupaten Karangasem. 2016. Kabupaten Karangasem Dalam Angka 2016. Badan Pusat Statistik Kabupaten Karangasem

BPN Kabupaten Karaaangasem. 2015. Peta Persebaran Tanah di Kabupaten Karangasem. Badan Pertanahan Nasional Kabupaten karangasem.

Dinas PUPR. Kabupaten Karangasem, 2016. Klasifikasi Jaringan Jalan di Kabupaten Karangasem. Bidang Bina Marga, Dinas PUPR Kabupaten Karangasem.

Gold, SM. 1980. Recreation Planningand Design. New York: Mc Graw-Hill Book Company. Lokakkarya. 2005. Ruang Terbuka Hijau (RTH) Perkotaan. Jakarta

Pemerintah Desa Pertima. 2016. Profil Desa Pertima. Pemerintah Desa Pertima.

Subadra, N. 2016. Dampak Ekonomi, Sosial-Budaya, Dan Lingkungan Pengembangan Desa Wisata Di Jatiluwih-Tabanan. Manajemen Pariwisata, Vol. 5, No.1: 46-64.

UNDP and WTO. 1981. Tourism Development Plan for Nusa Tenggara, Indonesia. Madrid: World Tourism Organization. Hal. 69

Zakarina, F. 2014. Konsep Pengembangan Kawasan Desa Wisata di Desa Bandungan Kecamatan Pakong Kabupaten Pamekasan. Teknik Pomits, Vol. 3, No.2: C245C249. 